\title{
Investigation of attractive forces between PECVD silicon nitride microstructures and an oxidized silicon substrate
}

\author{
P R Scheeper, J A Voorthuyzen*, W Olthuis and P Bergveld \\ MESA Research Insttute, Unwersity of Twente, PO Box 217, 7500 AE Enschede (Netherlands)
}

(Received November 6, 1990, in revised form September 5, 1991, dccepted November 8, 1991)

\begin{abstract}
A troublesome phenomenon encountered during the realization of free-standing microstructures, for example, beams, diaphragms and micromotors, is that initially released structures afterwards stick to the substrate This effect may occur durıng wafer drying after the etching process has been completed, as well as during normal operatıon as soon as released structures come into contact with the substrate In this paper the most important types of attractive forces are discussed with respect to their possible influence on the performance of micromachined structures It is concluded that the main reason for sticking of PECVD silicon nitnde micromachined structures is adsorption of water molecules The water molecules, adsorbed on both surfaces, attract cach other as soon as the surfaces comc into contact It is shown that a chemical surface modification, in order to achieve hydrophobic surfaces, is an effective method for avoıding adsorption of water, and therefore reduces sticking Stıcking of micromachıned structures during dryıng is reduced by rinsıng with a non-polar liquid before wafer dryıng
\end{abstract}

\section{Introduction}

Silicon micromachining has become an important tool for the fabrication of many types of mechanical sensors and actuators Examples are a recently developed capacitive pressure sensor and electret microphone [1] At the Unversity of Twente a condenser microphone with a silicon nitride diaphragm is being developed The movable diaphragm will be fabricated by means of sacrificial layer etching This process, which has also been used for the fabrication of beams [2] and micromotors [3], consists of the following successive steps First, the so-called sacrificial layer is deposited (evaporated aluminıum) and patterned, followed by the diaphragm material deposition (plasma-enhanced chemical vapour deposition (PECVD) of silicon nitride) Small access-holes are etched in the diaphragm material The movable diaphragm is formed by sacrificial layer etching via the access-holes The final step is drying the wafer with the diaphragms

Figure 1 shows a schematic cross section of a diaphragm after the etching of the sacrificial layer

\footnotetext{
*Present address Locamation, Auke Vleerstraat 26, 7521 PG Enschede, Netherlands
}

has been completed After rınsing with water or other liquids in order to remove the etchant, the wafer is still covered with liquid When the liquid above the diaphragm has evaporated, only the cavity under the diaphragm is filled with liquid This liquid evaporates through the access-holes in the diaphragm Adhesive forces between the shrinkıng liquid and the thin diaphragm pull the diaphragm towards the substrate It has been observed that, after all the liquid has disappeared, diaphragms may stick permanently to the underly-

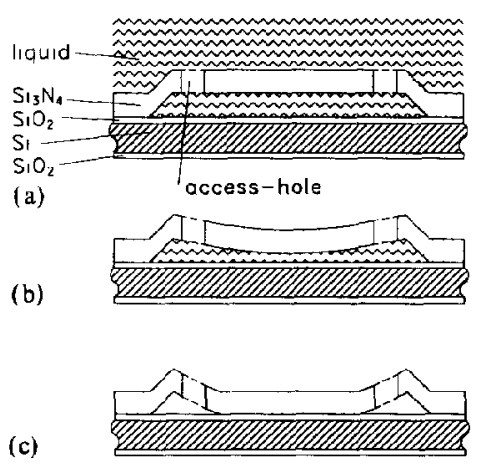

Fig 1 The drying process of diaphragms fabricated by means of sacrificial layer etching (a) after completion of sacrificial layer etching (b) only the arr gap filled with liquid. (c) the diaphragm stuck to the substrate 
ing substrate material Another effect that has been observed is that diaphragms, which have been dried without sticking, may stick to the substrate as soon as the surfaces come into contact with each other This may occur during normal operation due to (sound) pressure overload Both effects have also been described in the literature for other structures [2-5]

It is clear that an attractive force is present between the diaphragms and the substrate, with a magnitude inversely proportional to their separation During drying of the wafer, the evaporating liquid causes the diaphragms to contact the substrate The attractive force causes the diaphragms to remain stuck to the substrate

Linder and de Roolj [4] investigated sticking of doubly clamped polysilicon microbeams They used APCVD silicon dioxide as a sacrificial layer By applying a voltage between the beams and the silicon wafer, stuck beams could be released from the substrate It was concluded that sticking was caused by an electrostatic force

Mehregany et al [3] fabricated polysilicon micromotors using silicon dioxide as sacrificial layer They found that sticking occurred as soon as native oxide was formed on the silicon substrate and the polysilicon rotors It was assumed that because of the insulating native oxide layer, an electrostatic force would cause the sticking Guckel et al [2] suggested that stickıng was caused by the presence of an etch residue Lober and Howe [5] observed that water condensation between microstructures and the substrate may cause stıckıng

A technique to dry micromachined structures successfully has been developed by Guckel et al [2] After completion of sacrificial layer etching, the wafer is rinsed with a water/methanol mixture By applying a very rapid evaporation in a vacuum chamber, the liquid freezes Under carefully chosen conditions, the ice does not melt, but sublimes In this way the presence of liquid, and thus sticking during drying, is avoided Furthermore, the authors report that the attractive force causing sticking is elıminated by covering the substrate and the microstructures with LPCVD silicon n1tride

It can be concluded that no literature exists about sticking of PECVD silicon nitride microstructures The objective of this paper is to investigate systematically which type of attractive force causes stıckıng of released PECVD silicon nitride structures Silicon nitride cantilever beams and square diaphragms will be used as test structures and will be described in Section 2 In Section 3, several attractive forces that may cause sticking will be considered In Section 4, surface treatments to improve fabrication and operation will be presented

\section{Test structures and technology}

Besides diaphragms, silicon nitride cantilever beams have been used as test structures in order to study mechanical effects The cantilever beams and diaphragms have been realized on the same 2 inch p-type $510 \Omega \mathrm{cm}\langle 100\rangle$ silicon wafers First, the wafers were provided with thermally grown $\mathrm{SiO}_{2}$, with a thickness of $2100 \AA$ As a sacrificial layer, $1 \mu \mathrm{m}$ alumınıum was evaporated After patternıng the sacrificial layer, $1 \mu \mathrm{m}$ PECVD silicon nitride was grown for use as the beam and diaphragm material The conditions of the PECVD process are shown in Table 1 Diaphragm and beam structures were realized by reactive ion etching of the silicon nitride layer, followed by wet etching with a $\mathrm{H}_{3} \mathrm{PO}_{4} / \mathrm{CH}_{3} \mathrm{COOH} / \mathrm{HNO}_{3} / \mathrm{H}_{2} \mathrm{O} 805510$ mixture at a temperature of $50^{\circ} \mathrm{C}$ The wafers were dried in normal environmental air

The lateral dimension of the diaphragms was $200 \mu \mathrm{m}$ Cantilever beams have been made with a length of $100,200,300$ and $400 \mu \mathrm{m}$ and a width of 20 and $50 \mu \mathrm{m}$, resulting in eight different types of beams The mask layout of a test structure containing 16 cantılever beams is shown in Fig 2

The magnitude of the attractive force per unit area required for sticking of cantilever beams can be estımated by calculating the force per unit area, $P$, which causes a tip deflection $y$ of the cantilever beam This force per unit area is equal to

$$
P=\frac{2 E h^{3}}{3 L^{4}} y
$$

TABLE 1 The deposition conditions of the PECVD silicon nitride

\begin{tabular}{ll}
\hline Reactor & parallel plate (Electrotech PF 310) \\
Temperature & $300{ }^{\circ} \mathrm{C}$ \\
Pressure & $650 \mathrm{mTorr}$ \\
Power & $20 \mathrm{~W}$ \\
Frequency & $1356 \mathrm{MHz}$ \\
$\mathrm{S}_{1} \mathrm{H}_{4} / \mathrm{N}_{2}(2 \%)$ & $2000 \mathrm{sccm}$ \\
$\mathrm{NH}_{7}$ & $10 \mathrm{sccm}$ \\
\hline
\end{tabular}




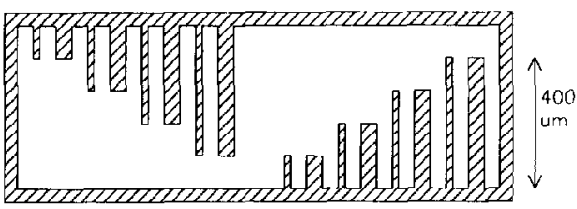

Fig 2 Mask layout of a testıng structure, contaming a total number of 16 cantilever beams with lengths of $100-400 \mu \mathrm{m}$ and a width of 20 or $50 \mu \mathrm{m}$

where $E$ is Young's modulus of the beam material, $h$ is the beam thickness and $L$ is the length of the beam Assuming the tip deflection $y$ to be equal to the distance between the beam and substrate, $P$ can be calculated for different values of $L$, using $E=10^{11} \mathrm{~N} / \mathrm{m}^{2}$ for silicon nitride, $y$ as $1 \mu \mathrm{m}$ and $h$ as $1 \mu \mathrm{m}$ The theoretical results are shown in Table 2 As can be seen from the SEM photograph in Fig 3 , free-standing beams show an upward curvature Thus the air gap is larger than $1 \mu \mathrm{m}$ and therefore the force per unit area required to cause stıcking will be higher than the values of Table 2

TABLE 2 The minımal force per unit drea required to cause sticking of cantlever beams, calculated for different cantlever beam lengths Young's modulus is $10^{11} \mathrm{~N} / \mathrm{m}^{2}$, beam thickness is $1 \mu \mathrm{m}$ and distance between beam and substrate is $1 \mu \mathrm{m}$

\begin{tabular}{ll}
\hline $\begin{array}{l}\text { Cantılever beam } \\
\text { length }(\mu \mathrm{m})\end{array}$ & $\begin{array}{l}\text { Force per unit } \\
\text { area }\left(\mathrm{N} / \mathrm{m}^{2}\right)\end{array}$ \\
\hline 100 & 670 \\
200 & 42 \\
300 & 8 \\
400 & 3 \\
\hline
\end{tabular}

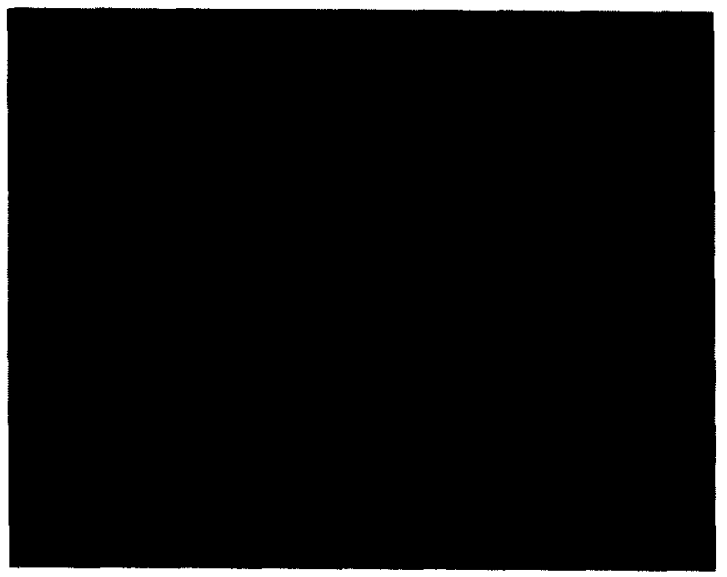

Fig 3 SEM photograph of stuck and released cantilever beams The released beams all show an upward curvature due to an internal bending moment in the beam material

\section{Investigation of attractive forces}

Stıckıng of cantılever beams may be caused by an internal bending moment in the beam material, which is a mechanical effect, or by different types of attractive forces The mechanical effect will be explained and investigated in Section 31 The most important types of attractive forces that may cause sticking of cantılever beams will be discussed in Sections 32-34

\section{Internal bending moment}

Free-standing cantilever beams have an average stress of zero, because they are clamped at only one side Note that the average stress is also zero if the beams are made of silicon nitride with tensile stress A non-uniform distribution of the stress across the thickness of the nitride layer always causes an internal bending moment, even in the case of zero average stress This moment causes cantilever beams to bend, in contrast with beams that are clamped at two sides An internal bending moment may cause the cantilever beams to bend downward, thus keeping the beams stuck to the substrate

To investıgate if stıcking of the cantilever beams is caused by an internal bending moment, stuck beams have been released from the substrate by means of a small probe As can be seen from the SEM photograph in Fig 3, released beams all showed an upward curvature, indicating the presence of an internal bending moment, but of opposite polarity to that required for the cantilever beams to stick Therefore, it can be concluded that the presence of an internal bending moment is not the reason why the beams stick to the substrate

\section{Electrostatic forces}

If the silicon nitride microstructure or the substrate contains a certain amount of fixed electric charge, an electric field will exist in the air gap between the beams or diaphragms and the substrate For two parallel plates, the attractive force per unit area, $P$, is

$P=\frac{1}{2} c_{0} E_{\mathrm{a}}{ }^{2}$

where $\varepsilon_{0}$ is the permittivity of the air gap and $E_{\mathrm{a}}$ is the constant electric field strength between both plates The force per unit area, $P$, can be made equal to zero if $E_{\mathrm{a}}=0$, which can be achieved by an external field that is opposite to the field caused 
by the built-1n charges This method has been applied successfully by Linder and de Rooi] [4]

The external voltage that is required to achieve a zero internal field can be estımated by considering a simplified representation of the structure connected to an external voltage source $V_{\mathrm{u}}$, as shown in Fig 4 The substrate is assumed to be conducting, and is covered with an $\mathrm{SiO}_{2}$ layer that contains a surface charge per unit area $\sigma_{\mathrm{ox}}$ Furthermore it is assumed that the silicon nitride diaphragm contains a surface charge per unit area $\sigma_{\mathrm{n}}$ The capacitances per unit area of the air gap, the $\mathrm{SiO}_{2}$ and the silicon nitride layer are $C_{\mathrm{d}}, C_{\mathrm{ox}}$ and $C_{n}$, respectively The charge present on the plates of $C_{\mathrm{d}}$ determines the electric field in the air gap, $E_{\mathrm{d}}$ Using Gauss's law, the electric field strengths in the silicon nitride, $E_{\mathrm{n}}$, the air gap, $E_{\mathrm{d}}$, and the $\mathrm{SiO}_{2}, E_{\mathrm{ox}}$, can be calculated as a function of the charges $\sigma_{n}$ and $\sigma_{o x}$ By elımınatıng $E_{n}$ and $E_{\mathrm{ox}}$ and applying $\oint E_{\mathrm{s}} \mathrm{ds}=0$, it can be shown that

$E_{\mathrm{d}}=\frac{C_{\mathrm{d}} C_{\mathrm{t}}}{\varepsilon_{0}\left(C_{\mathrm{t}}+C_{\mathrm{d}}\right)}\left[V_{\mathrm{u}}+\frac{\sigma_{\mathrm{n}}}{C_{\mathrm{n}}}-\frac{\sigma_{\mathrm{ox}}}{C_{\mathrm{ox}}}\right]$

where $\varepsilon_{0}$ is the permittivity of vacuum and

$C_{\mathrm{r}}=\frac{C_{\mathrm{ox}} C_{\mathrm{n}}}{C_{\mathrm{ox}}+C_{\mathrm{n}}}$

It can be seen from eqn (3) that $E_{\mathrm{d}}$ is equal to zero for

$V_{\mathrm{u}}=\sigma_{\mathrm{ox}} / C_{\mathrm{ox}}-\sigma_{\mathrm{n}} / C_{\mathrm{n}}$

$\left|V_{\mathrm{u}}\left(E_{\mathrm{d}}=0\right)\right|$ will be maximum if $\sigma_{\mathrm{ox}}$ and $\sigma_{\mathrm{n}}$ have opposite signs, and is given by

$\left|V_{\mathrm{u}}\left(E_{\mathrm{a}}=0\right)\right|=\frac{\left|\sigma_{\mathrm{ox}}\right|}{C_{\mathrm{ox}}}+\frac{\left|\sigma_{\mathrm{n}}\right|}{C_{\mathrm{n}}}$

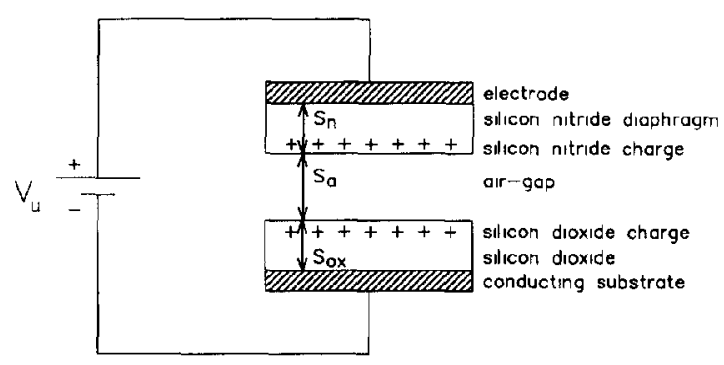

Fig 4 Schematic representation of a free-standing silicon nitride diaphragm provided with an electrode, and a conducting substrate covered with a silicon dioxide layer The upper electrode and the substrate are connected by an external voltage source $V_{\mathrm{u}}$
A charged insulator can be characterized by its built-in voltage $V$, which is related to the surface charge per unit area, $\sigma$ For the $\mathrm{S}_{1} \mathrm{O}_{2}$ and $\mathrm{S}_{3} \mathrm{~N}_{4}$ layers the voltages are given by

$V_{\mathrm{ox}}=\frac{\sigma_{\mathrm{ox}} s_{\mathrm{ox}}}{\varepsilon_{0} \varepsilon_{\mathrm{ox}}}=\frac{\sigma_{\mathrm{ox}}}{C_{\mathrm{ox}}}$

$V_{\mathrm{n}}=\frac{\sigma_{\mathrm{n}} s_{\mathrm{n}}}{\varepsilon_{0} \varepsilon_{\mathrm{n}}}=\frac{\sigma_{\mathrm{n}}}{C_{\mathrm{n}}}$

where $s_{\mathrm{ox}}, s_{\mathrm{n}}$ and $\varepsilon_{\mathrm{ox}}, \varepsilon_{\mathrm{n}}$ are the thicknesses and the relative dielectric constants of $\mathrm{S}_{1} \mathrm{O}_{2}$ and $\mathrm{Si}_{3} \mathrm{~N}_{4}$, respectively, and $\varepsilon_{0} \varepsilon_{\mathrm{ox}} / s_{\mathrm{ox}}, \varepsilon_{0} \varepsilon_{\mathrm{n}} / s_{\mathrm{n}}$ are equal to the $\mathrm{S}_{1} \mathrm{O}_{2}$ and $\mathrm{S}_{3} \mathrm{~N}_{4}$ capacitances per unit area, $C_{\mathrm{ox}}$ and $C_{\mathrm{n}}$ The voltages $V_{\mathrm{ox}}$ and $V_{\mathrm{n}}$ can easily be measured with a vibrating reed electrostatic voltmeter [6] However, measurements with a Monroe Isoprobe 244 electrostatic voltmeter have shown that the built-1n voltages of $\mathrm{SlO}_{2}$ and $\mathrm{Sl}_{3} \mathrm{~N}_{4}$ layers, fabricated as described in Section 2, were both below the detection threshold of this instrument, which is $1 \mathrm{~V}$ Thus $\left|V_{\text {ox }}\right|<1 \mathrm{~V}$ and $\left|V_{\mathrm{n}}\right|<1 \mathrm{~V}$ Assuming $V_{\text {ox }}$ and $V_{\mathrm{n}}$ to be equal to $1 \mathrm{~V}$, an upper limit for the value of $\mid V_{\mathrm{u}}\left(E_{\mathrm{a}}=0\right)$ (can be calculated using eqns (6a), (6b) and (5) The upper limit for $\left|V_{\mathrm{u}}\left(E_{\mathrm{u}}=0\right)\right|$ is $2 \mathrm{~V}$, so $\left|V_{\mathrm{u}}\left(E_{\mathrm{a}}=0\right)\right| \leqslant 2 \mathrm{~V}$

The internal field compensation test has been cariled out with $200 \mu \mathrm{m} \times 200 \mu \mathrm{m}$ silicon nitride diaphragms, provided with aluminium electrodes Using a Hewlett Packard 4145 B parameter analyser, the external voltage was swept between -30 and $+30 \mathrm{~V}$ using steps of $100 \mathrm{mV}$ It was not possible to release stuck diaphragms this way Using higher voltages it was observed that the contacting area between the diaphragms and the substrate increased This indicates that the attractive force, caused by the externally applied electrostatic field, increases Therefore it is not to be expected that voltages of more than $30 \mathrm{~V}$ will release stuck diaphragms

According to eqn (3), an electrostatic altraction can always be elrminated by compensating the internal electric field However, by sweeping the external voltage in a theoretically predicted range it has not been possible to release stuck diaphragms Considering these results, it can be concluded that, in our case, sticking is not caused by electrostatic attraction Note that some built-in charge may have been present in the diaphragm material or the silicon dioxide layer, but this is not the main reason for sticking 


\section{Van der Waals forces}

The attraction between neutral atoms or nonpolar molecules, with a mutual separation too large to cause their electron clouds to overlap, is called the van der Waals force Its origin is that atoms or molecules without a static dipole moment exhibit a fluctuating dipole moment, due to the fact that electrons are not able to screen the charge of the atomic nucleus in all directions at one and the same moment because of their motion

As a consequence of the van der Waals attraction between atoms, this type of attraction is also present between macroscopic bodies The force between macroscopic bodies can be calculated by summation of the forces between individual atoms or molecules of the bodies By means of this microscopic theory, it has been shown that the attractive force per unit area, $P$, between two flat, infinite plates is [7]

$$
P=A / 6 \pi D^{3}
$$

where $D$ is the distance between the plates and $A$ is a so-called Hamaker constant Equation (7) is only valid for distances less than about $10 \mathrm{~nm}$ These short-range van der Waals forces are called normal van der Waals forces

As the distance between the plates becomes larger, the attractive force per unit area can be written as [7]

$P=B / D^{4}$

where $\boldsymbol{B}$ is a Hamaker constant for long-range van der Waals attraction These long-range van der Waals forces are called retarded van der Waals forces

Using eqns (7) and (8), the van der Waals force per unit area can be calculated as a function of the mutual distance between two flat plates Figure 5 shows the calculated force per unit area for $\mathrm{SiO}_{2}$ plates, using $A=54 \times 10^{-20} \mathrm{~J}$ and $B=10^{-28} \mathrm{~J} \mathrm{~m}$ [8] Values for the Hamaker constants of PECVD silicon nitride are not avalable

Comparing the results of Table 2 and Fig 5, theoretically the van der Waals force between the free-standing beams and the substrate can become strong enough to cause sticking if their mutual separation is less than about $10-100 \mathrm{~nm}$, of course depending on the length of the beams It will be clear that the effective distance between the mlcrostructures and the substrate is determined by

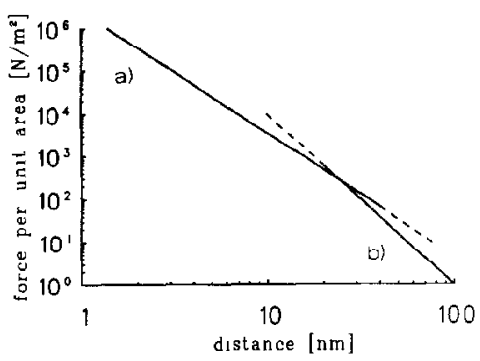

Fig 5 The van der Waals force per unit area between two flat, infinite plates as a function of distance The calculation is based on literature values for $\mathrm{SiO}_{2}\left(A=54 \times 10^{20} \mathrm{~J}\right.$ and $\left.B=10^{28} \mathrm{~J} \mathrm{~m}\right)$ [6] (a) normal forces (eqn (7)) (b) retarded forces (eqn (8))

their surface roughness, which will result in such a large uncertainty in the measured van der Waals force that these measurements will not be reliable and are therefore not performed Therefore it can only be concluded that the van der Waals force is theoretically able to cause stıckıng

\section{Water adsorption}

If an $\mathrm{SlO}_{2}$ or $\mathrm{Sl}_{3} \mathrm{~N}_{4}$ surface is surrounded by humid air, water molecules are absorbed to the surface Adsorption can be divided into chemisorption and physisorption Chemisorbed water molecules are chemically bonded to the surface as hydroxyl ( $-\mathrm{OH})$ groups Physisorbed water molecules are hydrogen bonded to the hydroxyl groups This is shown schematically in Fig 6(a) If two surfaces are contacted, an attraction may occur between the adsorbed water molecules This is shown schematically in Fig 6(b) Stengl et al [9] have shown that two oxidized silicon wafers bond as soon as they touch because

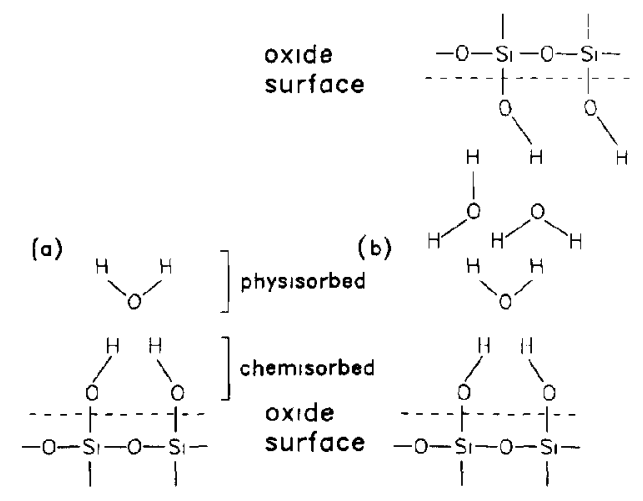

Fig 6 (a) $\mathrm{SiO}_{2}$ surface after adsorption of water (b) Two $\mathrm{SiO}_{2}$ surfaces kept together by hydrogen bonding between physisorbed water molecules as proposed by Stengl et al [7] - = chemical bond = hydrogen bond 
of this mechanism They calculated a surface energy of $104 \mathrm{~mJ} / \mathrm{m}^{2}$ for the bonded wafers The bond between bonded wafers is very strong Values of $2-5 \times 10^{5} \mathrm{~N} / \mathrm{m}^{2}$ have been measured by Shimbo et al [10] Therefore this mechanism is expected to be a possible cause for sticking

If sticking of free-standing silicon nitride microstructures to the oxidized silicon substrate is caused by water adsorption, the sticking would be correlated with the presence of adsorbed water molecules The adsorption of water on $\mathrm{SiO}_{2}$ surfaces can be described by the BET adsorption theory, which predicts that only a certain fraction $R_{\mathrm{c}}$ of the total surface is covered with one or more monolayers of physically adsorbed water molecules This fraction can be written as a function of the relative humidity of the surrounding air [11]

$R_{\mathrm{c}}=\frac{C h}{1+(C-1) h}$

where $h$ is the relative humidity and $C$ is a dimensionless constant, which is approximately 004 for $\mathrm{S}_{1} \mathrm{O}_{2}$ [11] It can be concluded from eqn (9) that adsorbed water molecules can be removed from the surfacc $\left(R_{\mathrm{c}}=0\right)$ by making the relative humidity equal to zero

A zero relative humidity has been realızed by placing the samples in a continuous flow of dry nitrogen Adsorption of water molecules occurred when a test sample was exposed to room air with a relative humidity of $40-50 \%$ Three test samples, each containıng five test structures as shown in Fig 2, with initially stuck beams have been used for this experiment The cantilever beams have first been released from the substrate with a small probe After this release the test samples were placed in a dry (nitrogen) or a humid (air) env1ronment for a period of $3-4 \mathrm{~h}$ to enable the adsorption or desorption process to reach an equilibrium situation The attractive forces in a dry nitrogen ambient and in a humid alr environment have been compared by contacting the beams with the substrate This has been done by pushing on top of the beams with the probe and pressing the beams and substrate together After each test, the number of beams that remained stuck to the substrate was counted

The experiment was repeated alternately in humid air $(h=40-50 \%)$ and dry nitrogen The resultıng stickıng ratıos are shown in Table 3 The
TABLE 3 The dverage sticking ratio of silicon nitride cantilever beams in humid air (rclative humidity 40-50\%) and dry nitrogen as a function of the beam length Beam thickness is $1 \mu \mathrm{m}$ All samples contained 20 beams of each length

\begin{tabular}{lll}
\hline $\begin{array}{l}\text { Beam length } \\
(\mu \mathrm{m})\end{array}$ & Stıcking ratio & \\
\cline { 2 - 3 } & Humid air & Dry nitrogen \\
\hline 400 & 063 & 019 \\
300 & 041 & 005 \\
200 & 011 & 001 \\
100 & 0 & 0 \\
\hline
\end{tabular}

stıckıng ratio is defined as

stıckıng ratıo $=\frac{\text { number of stuck beams }}{\text { total number of beams }}$

The values from Table 3 are the average sticking ratios of the three test samples It can be observed from Table 3 that the sticking ratio decreases in dry nitrogen, and increases with increasing beam length This is expected, because less force per unit area is required to deflect longer cantılever beams, as calculated in Table 2 Furthermore it was observed that the sticking ratio was a reversible function of the relative humidity

Thus a correlation between the attractive force and the presence of adsorbed water molecules is obviously present It can be concluded that adsorption of water molecules on the beams and the substrate is a main factor for sticking under normal environmental circumstances Another force also seems to contribute to the sticking, because in a dry nitrogen atmosphere some beams are always able to stick to the substrate However, this second force is of minor importance

\section{Surface treatments}

In Section 3 it was shown that stıcking of freestanding microstructures is mainly caused by the presence of water molecules adsorbed on the surfaces It is very likely that stıckıng durıng drying of microstructures is due to the same effect To produce free-standing microstructures, which can operate in a normal (humid) environment, both stıckıng durıng dryıng and durıng normal operation should be avolded Therefore, a treatment to avoid stıckıng during drying of the microstructures 
and a surface treatment to avoid adsorption of water afterwards will be discussed here

\section{Rinse procedures}

During drying of micromachined structures, the withdrawing liquid film between the structures and the substrate pulls the surfaces together as soon as only the air gap under the microstructures is filled with liquid Once the surfaces touch, they are kept together by the attractive forces between adsorbed water molecules Stickıng during drying of the microstructures may be reduced or even eliminated if the adhesive force between the withdrawing liquid and the microstructures or the substrate is minimized The force, caused by the liquid, is a function of the surface tension of the liquid and the contact angle between the liquid and the surface In general, a lower surface tension will result in a smaller force Furthermore, rinsing with another liquid will remove water from the air gap between the beams and the substrate Therefore it is expected that rinsing with a liquid with a lower surface tension after completion of sacrificial layer etching will reduce the sticking ratio

The following rinse cycles have been tested after completion of the sacrificial layer etching First, rinsıng with deionized (DI) water only Next, rınsing with DI water and ethanol and, finally, rinsing with DI water, ethanol and $n$-hexane Rinsing with ethanol before rinsing with n-hexane is necessary, because (non-polar) n-hexane cannot be mixed with (polar) water After the samples have been dried in normal environmental air, the number of stuck beams is counted Table 4 shows the results

As can be seen from Table 4, rinsing with a non-polar liquid reduces the number of stuck beams

\section{Hydrophobic surface modification}

Free-standing micromachined structures may stick as they come into contact with the substrate

TABLE 4 The average sticking ratio as a function of the length of the cantilever beams after different rinse cycles All samples contained 20 beams of each length

\begin{tabular}{llll}
\hline $\begin{array}{l}\text { Beam length } \\
(\mu \mathrm{m})\end{array}$ & DI water & $\begin{array}{l}\text { DI water, } \\
\text { ethanol }\end{array}$ & $\begin{array}{l}\text { DI water, } \\
\text { ethanol } \\
\text { n-hexane }\end{array}$ \\
\hline 400 & 10 & 098 & 082 \\
300 & 10 & 095 & 068 \\
200 & 10 & 093 & 028 \\
100 & 10 & 095 & 0 \\
\hline
\end{tabular}

during normal operation due to the presence of adsorbed water molecules from environmental humid air To avoid adsorption of water molecules on the surface, it should be hydrophobic One method to replace polar hydroxyl groups by nonpolar groups is a chemical surface modification with hexamethyldisilazane (HMDS) [12] The -OH groups on the silicon dioxide or silicon nitride surface are then replaced by non-polar $-\mathrm{O}-\mathrm{S} 1\left(\mathrm{CH}_{3}\right)_{3}$ groups

Samples with cantılever beams, which have been released with a probe, have been used to invest1gate the effect of a vapour phase HMDS treatment All samples contaned 96 cantilever beams Two samples were left untreated and two samples were treated with $\mathrm{HMDS}$ vapour at $120^{\circ} \mathrm{C}$ for $30 \mathrm{~min}$ The attractive force between the beams and substrate has been tested in humid air by deliberately contacting the surfaces with a probe, as explained in Section 34 The average sticking ratios arc shown in Table 5

Too many of the $100 \mu \mathrm{m}$ long beams were damaged during release from the substrate Therefore no conclusions have been drawn from the results of these beams It can be observed from Table 5 that the sticking ratio of the $200 \mu \mathrm{m}$ long beams is significantly reduced by the HMDS treatment The sticking ratio of the 300 and $400 \mu \mathrm{m}$ long beams shows no significant decrease Furthermore 1t was observed that the contact area between stuck beams and the substrate of the HMDStreated beams was typically less than $10 \%$ of the total beam area The contact area of the untreated beams was about $50 \%$ of the total beam area

The sticking ratios from Table 5 for untreated beams in humid air are higher than the values shown in Table 3 This is because the beams used for testing the HMDS treatment were fabricated in another batch The free-standing cantilever beams

TABLE 5 The average sticking ratio as a function of the beam length of untreated and HMDS-treated samples with released cantılever beams after deliberately contacting the beams with the substrate in normal environmental air $(h=40.50 \%)$ All samples contained 24 beams of each length

\begin{tabular}{|c|c|c|}
\hline \multirow{2}{*}{$\begin{array}{l}\text { Beam length } \\
(\mu \mathrm{m})\end{array}$} & \multicolumn{2}{|c|}{ Sticking ratıo } \\
\hline & Untreated & HMDS treated \\
\hline 400 & 10 & 10 \\
\hline 300 & 10 & 098 \\
\hline 200 & 096 & 002 \\
\hline
\end{tabular}


of this batch showed less upward curvature than the beams shown in Fig 3 Therefore these beams do stick more easily to the substrate, as explained in Section 2, and higher sticking ratios are expected

As shown in Section 34, adsorption of water molecules is the main reason for sticking of PECVD silicon nitride cantilever beams Modification of the hydrophilic surface into a hydrophobic one reduces water adsorption The number of stuck beams with a length of $200 \mu \mathrm{m}$ decreases significantly after HMDS treatment The sticking ratio of the 300 and $400 \mu \mathrm{m}$ long beams is not reduced significantly In Table 2 it was shown that a smaller force per unit area is required to cause stıcking of longer cantilever beams Therefore it may be concluded that the attractive force between the beams and the substrate has been reduced by the hydrophobic surface modification, but is still able to cause stickıng of the longer cantilever beams The HMDS treatment is a useful way to reduce sticking of microstructures during normal opcration

\section{Discussion and conclusions}

A correlation between the sticking of initially released PECVD silicon nitride cantilever beams and the relative humidity of the surrounding air has been found It can be concluded that adsorbed water molecules on the surfaces attract each other as soon as the surfaces are brought into contact Stengl et al [7] have found that water adsorption causes direct bonding of polished silicon wafers at room temperature Apparently, the same mechanism is responsible for both phenomena

It was not possible to reproduce the experiment of Linder and de Rool] [4] using PECVD sllicon nitride diaphragms Stuck diaphragms could not be released by applying a voltage between the diaphragm and the substrate In our experiments the silicon under the diaphragm was undoped, and therefore some voltage drop will occur across the depletion region when the air-gap capacitor is reversely biased However, this was not the reason why it was impossible to release the diaphragms, because the voltages have been investigated up to values higher than +30 or $-30 \mathrm{~V}$, where the attraction only increased, as explained in Section 32

It was observed in Sections 34 and 42 that some of the untreated beams in a dry nitrogen atmosphere, as well as the relatively long HMDStreated beams, are able to stick to the substrate Apparently, another force also contributes to the sticking This may be van der Waals forces, as explained in Section 33, or electrostatic forces However, the main reason for the sticking of PECVD silicon nitride cantilever beams is adsorption of water molecules, and the other forces are of minor importance

The fabrication of PECVD silicon nitride cantilever beams has been improved by rinsing with non-polar $n$-hexane after completion of sacrificial layer etching In order to avoid stickıng of microstructures during normal operation, water adsorption should not occur A hydrophobic surface modification with HMDS has been shown to reduce stıckıng

Summarizing, it can be stated that the fabrication and operation of micromachined devices can be improved by applying the rinse procedures and surface treatments discussed in this paper

\section{Acknowledgements}

The authors wish to thank Mr B Otter for producing the SEM photograph

\section{References}

1 J A Voorthuyzen, P Bergveld and A J Sprenkels, Semiconductorbased electret sensors for sound and pressure IEEE Trans Elect Insul, 24 (1989) 267-276

2 H Guckel J J Sniegowsk1 T R Christenson, S Mohney and $T$ F Kelly, Fabrication of micromechanical devices from polysilicon films with smooth surfaces, Sensors and Actuators, 20 (1989) $117-122$

3 M Mehregany, P Nagarkar S D Senturia and J H Lang. Operation of microfabricated harmonic and ordinary side-drive motor Proc IEEE MEMS, Napa Valley CA, USA, Feb 1990, pp $1-8$

4 C Linder and N F de Roolj, Investigations on free-standing polysilicon beams in view of their application as transducers Sensors and Actuators A2I-A23 (1990) 1053-1059

$5 \mathrm{~T} A$ Lober and R T Howe. Surface-micromachining processes for electrostatic microactuator fabrication, Proc IEEE Solid-State Sensor and Actuator Workshop, Hilton Head Island, SC, USA June 6-9, 1988, pp 59-62

6 G M Sessler, Electrets Topis in Applied Physics, Vol 33 Springer Berlin Ist edn 1980 p 42

$7 \mathrm{~J} \mathrm{~N}$ Israelachvilı and D Tabor, The measurement of van der Waals dispersion forces in the range 15 to $130 \mathrm{~nm}$. Proc $R$ Soc London. Ser A, 33I (1972) 19-38

$8 \mathrm{~J}$ Haisma, G A C M Spıerıngs, U K P Biermann and J A Pals Silicon-on-insulator wafer bonding-wafer thinning technolog1cal evaluations $J p n J$ Appl Phys 28 (1989) 14261443 
9 R Stengl, T Tan and U Gosele, A model for the sllicon wafer bonding process, Jpn $J$ Appl Phys 28 (1989) 1735-1741

10 M Shimbo, F Furukawd, K Fukuda and K Tanzawa, Siliconto-silon direct bonding method, $J$ Appl Phvs 60 (1986) 29872989

11 R Castagne P Hesto and A Vapalle Surface conductivity of the insulator of an MIS or MIM device, Thin Soltd Films, it (1973) 253-264

$12 \mathrm{~J}$ A Voorthuyzen $\mathrm{K}$ Keskın and $\mathrm{P}$ Bergveld Investigdtions of the surface conductivity of silicon dioxide and methods to reduce It, Surf SCl 187 (1987) 201-21I

\section{Biographies}

Patrick Richard Scheeper was born in Nieuw Vennep, Netherlands, on October 25, $1965 \mathrm{He}$ received the $\mathrm{B} S$ degree in applied physics from the Rooms Katholieke Hogere Technische School R1jswijk, Rijswijk, Netherlands, in 1988 In the same year he joined the Bio-Information Group, Department of Electrical Engineering, University of Twente, Netherlands His current research is focused on the development of a microphone based on silicon technology for use in hearing aids

Johannes Arle Voorthuyzen was born in Capelle a/d IJssel, Netherlands, on April 22, $1959 \mathrm{He}$ received the $\mathrm{MS}$ degree in electrical engineering from the Delft University of Technology, Delft, Netherlands, in 1982 In the same year he joined the B1o-Information Group, Department of Electrical Engineering, University of Twente, Enschede, Netherlands, where he recelved his $\mathrm{Ph} \mathrm{D}$ degree in 1986 His research was focused on sensors for biomedical applications Since 1990 he has been employed by Locamation B V
Wouter Olthuis was born in Apeldoorn, Netherlands, on October 23, 1960 He recelved the M S degree in electrical engineering from the University of Twente, Enschede, Netherlands, in 1986 In the same year he joined the Biomedical Engineering Division of the Faculty of Electrical Engineering, University of Twente, Enschede, Netherlands, where he received his $\mathrm{Ph} \mathrm{D}$ degree in 1990 Currently, he is working as an assistant professor in the biosensor technology group of the University of Twente

Piet Bergveld was born in Oosterwolde, Netherlands, on January 26, $1940 \mathrm{He}$ recelved the M S degree in electrical engineering from the University of Eindhoven, Netherlands, in 1965 and the $\mathrm{Ph} \mathrm{D}$ degree from the University of Twente, Netherlands, in 1973 The subject of his dissertation was the development of ISFETs and related devices, the actual invention of the ISFET, since then also investigated by many other international research groups of Universities as well as industry

Since 1965 he has been a member of the Biomedical Engineering Division of the Faculty of Electrical Engineering (University of Twente) and was in 1984 appointed as full professor in Biosensor Technology $\mathrm{He}$ is one of the project leaders in the MESA Research Institute

His research subjects still concern the further development of ISFETs and biosensors based on ISFET technology, as well as silicon microphones, resulting up to now in more than 150 papers 